\title{
Glycogen Storage Disease Type III
}

National Cancer Institute

\section{Source}

National Cancer Institute. Glycogen Storage Disease Type III. NCI Thesaurus. Code C84736.

An autosomal recessive inherited type of glycogen storage disease caused by deficiency

of the glycogen debranching enzyme. It results in the accumulation of structurally abnormal glycogen in the heart, skeletal muscles, and/or liver. 